SAND89-2444

Unlimited Release

Printed October 1990
Distribution $\$ 20$
Category UC- $\$ 8$

\title{
CASK SYSTEM DESIGN GUIDANCE. FOR ROBOTIC HANDLING
}

J. M. Griesmever, W. D. Droming, and A, K. Morimoto

Intelligent Machine Systems

and

P. C. Bennett

Transportation Systems Development

Sandia National Laboratories

Alouquerque. NM 87185

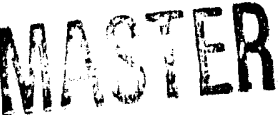

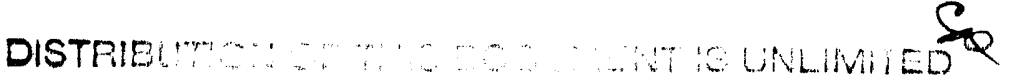




\begin{abstract}
Remote automated cask handling has the potential to reduce both the occupational exposure and the time required to process a nuclear waste transport cask at a handling facility. The ongoing Advanced Handling Technologies Project (AHTP) at Sandia National Laboratories is described. Results obtained from the project which impact the design of nuclear waste transport casks are addressed. AHTP was initiated to explore the use of advanced robotic systems to perform cask handling operations at handling facilities for radioactive waste, and to provide guidance to cask designers regarding the impact of robotic handling on cask: design. The proof-of-concept robotic systems developed in AHTP are intended to extrapolate from currently available commercial systems to the systems that will be available by the time that a repository would be open for operation. The project investigates those cask handling operations that would be performed at a nuclear waste repository facility during cask receiving and handling. The ongoing AHTP indicates that design guidance, rather than design specification, is appropriate, since the requirements for robotic handling do not place severe restrictions on cask design but rather focus on attention to detail and design for limited dexterity. The cask system design features that facilitate robotic handling operations are discussed, and results obtained from AHTP design and operation experience are summarized. The application of these design considerations is illustrated by discussion of the robot systems and their operation on cask feature mock-ups used in the AHTP project. Concepts being explored during the preliminary design of transportation casks for spent fuel transport are reviewed with regard to their implications for robotic handling.
\end{abstract}


Table of Contents

INTRODUCTION

SELECTION OF ROBOTIC OPERATIONS

IMPACT OF ROBOTIC HANDLING ON CASK SYSTEM DESIGN

ILLUSTRATIONS OF CASK DESIGN CONSIDERATIONS

A. Remote Radiation Survey and Analysis System (RRSAS) 7

B. Cask Head Operations (CHO) 9

C. Impact Limiters 11

1. Cylindrical Impact Limiter 14

2. Conical (Tapered Mating) Impact Limiter 16

$\begin{array}{ll}\text { D. Tiedown Systems } & 17\end{array}$

1. Rigid Strap Tiedown Design 18

2. Trunnion Tiedown Design 19

3. Dual Trunnion Tiedown Design 21

REVIEW OF PRELIMINARY CASK DESIGN CONCEPTS 22

A. Inspection 23

B. Personnel Barriers 23

C. Impact Limiters 24

D. Tiedowns 26

$\begin{array}{ll}\text { E. Ports } & 27\end{array}$

F. Closures $\quad 28$

G. Cask Lifting Method $\quad 29$

$\begin{array}{lr}\text { CONCLUSIONS } & 29\end{array}$

ACK NOWLEDGEMENTS 30

REFERENCES 31 


\section{INIRODICTION}

Sandia National Laboratories (SNL) supports the U.S. Department of Energy (DOE) (office of Civilian Radioactive Waste Management and Office of Environmental Restoration and Waste Management in the development of technology for the safe transport of nuclear waste. Part of that development effort includes investigation of advanced handling technologies, administered through the DOE Idaho and +t uquerque Operations Offices, for automation of cask handling operations at nuclear waste handling facilities. Although low radiation levels are anticipated near waste transport casks, cumulative occupational exposure at a repository can be significant.

Remote automated cask handling has the potential to reduce both the occupational exposure and the time required to process a cask. Thus, automated handling is consistent with DOE efforts to reduce the lifecycle costs of the waste disposal system and to maintain public and occupational radiological risks as low as reasonably achievable $[1]$.

This repuit describes the ongoing Advanced Handling Technologies Project (AHTP) at SNI, and those results obtained from the project which impact the design of nuclear waste transport casks. AllTP was initiated to explore the use of advanced rohotic systems to perform cask handling operations at radioactive waste handling facilities and to provide guidance to cask designers regarding the impact of robotic handling on cask design. The development of advanced robotic istems at SNL focuses on the use of model based control with sensor systems to correlate the mathematical models of the environment, manipulated objects, and robots to the actual physical (objects and to provide robust and intelligent error defection and recovery. The proof-of-concept systems devel,ped in AHTP are intended to extrapolate from currently available commercial systems to the systens that would be available by the cime that an actual repository would be open for operation. These projects investigate cask handling operations that would be performed at a fuclear waste repository facility during cask receiving and handling.

This report is an update of a previous report on the implications of robotic handling on cask astem design [2]. The ongoing AitTP at SNI. indicates that design guidance, rather than design 
specificalion. is appropriate, since the requirements for robotic handling do not place severe restrictions on cask design but rather focus on attention to detail and design for limited dexterity.

The first section describes the approach used in AHTP to select sperations for proof-of-concept robotic systems and to identify the cask design implications. In the next section, the cask system design features that facilitate robotic handling operations are discussed, and results obtained from AHTP design and operation experience are summarized. Next, the application of these design considerations is illustrated by discussion of the cask feature mock-ups used in the AHTP project. Finally, concepts being explored d rring the preliminary design of transportation casks for spent fuel liansport are reviewed with regard to their implications for robotic handling.

An earlier report [2] describes the characteristics of robotic manipulator systems and their application to a preliminary design concept for the transportation and repository interface. In that report, the interaction between cask design features and robotic handling was presented, based on experience with the Remote kaoiation Survey and Analysis System (RRSAS). This report expands the earlier work, drawing on experiences gained in the design and operation of additional proof-of-concept systems in AHTP.

\section{SELECTION OF RGBOTIC OPERATIONS}

The Advanced Handling Technologies Project was initiated to provide guidance to transport cask designers regarding designs to accommodate remote and robotic handling at nuclear waste handling facilities. The basic approach used in AHTP to develop insights on the interaction between cask system design and robotic performance of handling operations is to 1) select uperalions than might be performed robotically, 2) build profl-of-concent systems to investigate those operations, and 3) identify how cask system design features interaci with the performance of the robotic systems.

Selection of operations for which to build proof-of-concept robotic systems was based upon the 
estimates of the radiological dose associated witn cask handling operations, the need for development of enabling robotic systems technology, and potential implications on cask safety features [3]. The operations that result in the largest doses when performed manually are 1) cask head operations includinz bolting/unbolting and gas samp!ing, 2) removal of impact limiters and cask liedowns, 3) washdown including radiation and contamination surveys, and 4) removing the cask from its transporter and placing it on a cart for transport within the handling facility [4]. The high dose from these operations results from the radiation field close to the loaded cask, the time required to perform the operations, and the frequency of the operations.

AHTP consists of several subprojects that address the high dose operations mentioned above. The proof-of-concept robotic systems developed in AHTP start with the findings of the Hanford Engineering Development Laboratory (HEDL) cask handling work [5] and incorporate advanced technological features that are expected to become commercially available over the next $5-15$ years. Much of the control for future robot systems will be through supervisory computers using models of the robots and their environment including manipulated objects. Sensor-based control (e.g., force control) currently demonstrated in laboratory systems [6] will be available. While vision systems will be available to locate objects and build the models of the environment used by robotic systems, vision-based servo control may not be available in commercial systems in the next $5-15$ years. The use of computer nociels allows for intelligent error recovery when model-based expectations are not met. This results in reliable system operation. The proof-ofconcept robot systems developed for AHTP emphasize the integration of sensur information such as force and vision into model-based supervisory control of the various robot system components. These laboratory robotic systems $[7,8]$ have already demonstrated significant progress in modes based supervisory control. Based on experience in the design and operation of these systems, insights into the impact of robotic handling on cask design features have been developed and are discussed in the next section. 


\section{INPACT OF ROBOTIC HANDLING ON CASK SYSTEM DESIGN}

Table I summarizes preliminary design guidance to facilitate remote handling [2]. (Critical to the success of the model-based supervisory control used in AllTP and expected to be a fundamental part of future robotic systems is the computer model of the robot and the objects in its environment. The model allows the supervisory computer to interpret sensory data and automatically direct robot motions based upon this sensory information. Simple cask geometries greatly facilitate task planning and supervisory control using models Thus, cask design should employ geometries that are as simple as possible without compromising cask performance. Model-based control of commercial robots incorporating a single force sensor in proof-ofconcept systems has allowed robots to perform a wide range of contact-based manipulation tasts such as mechanical assembly [8] and radiological swiping [7] previously not demonstrated. In fact. radiological swiping operations in the AHTP proof-of-concept system for RRSAS could be performed faster robotically than manually due in part to the use of a cask mock-up witis well defined geometries.

Cask design for robotic handling must accommodate the limited dexterity of robots. limited degrees of freedum and the reliance on special tools to perform various tasks require that clearances be provided on the cask for the approach of the often bulky end effector and 100 l changer mechanism. The extra clearance required because of robot system position and sensor crrors is on the order of 0.5 inches for the RRSAS system. In 5-15 years robot systems might reduce that error to about 0.05 inches [2]. However, approaches that require the rwbot to thread through or reach around obstacles must provide clearances for the robot arm as well as the attached tool. For example, special clearance considerations were required for placement of the attachment bolts for one of the AllTP impact limiter mock-up designs that was attached wo the cask with bolts from the cask side of the limiter rather than from the asik end. The cxpenit of the robotic systems and path planning constraints provide incentive to employ only one multifunction robot in a given workspace. Overhead gantry robots are likely candidales hecause of their large workspace. Thus, clearances for straightline overhead apmoraches are decinable. 


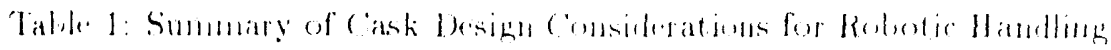

\section{Configunation and Construction}

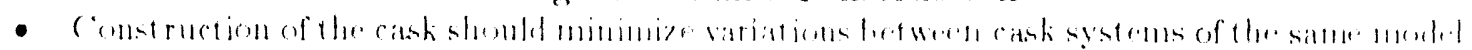

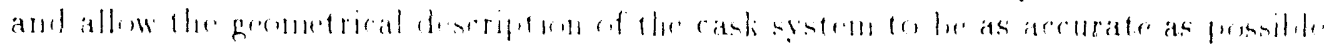

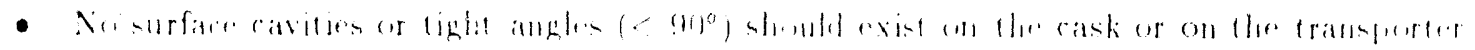

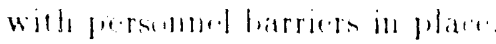

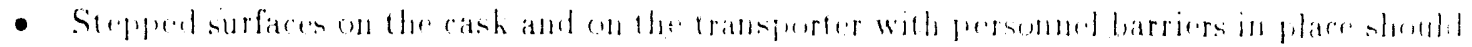
lie minimized

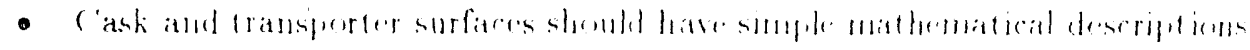

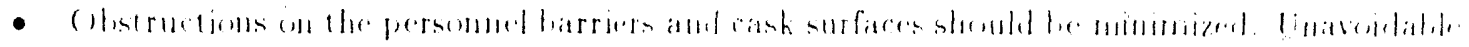

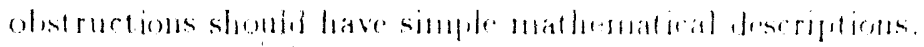

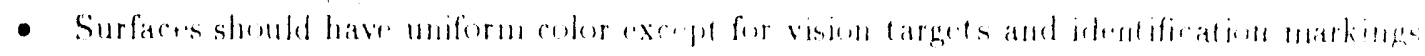

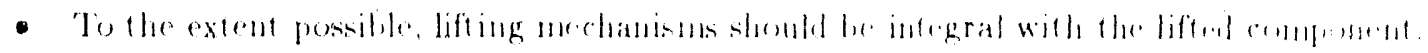

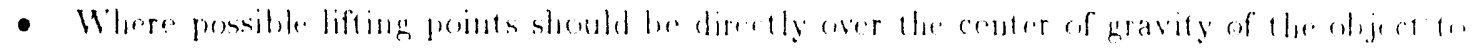
li, liftil

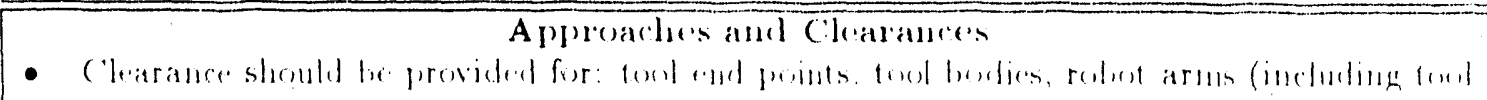
mount plates) and manewaring.

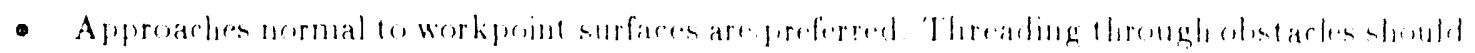
not be required lo reach a workforillt.

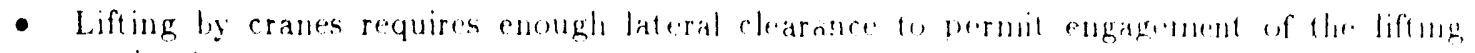
neechanisms

Mating and Engatgement of Components
- Self-guided mating shombl he provided lo arommondate aligmment errors.

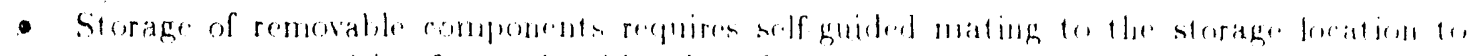
ensure proper position for retrinath ty the roteret or cratle.

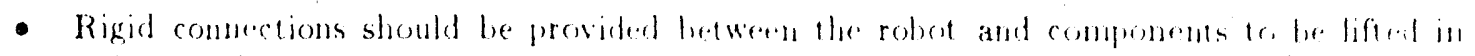
order to minimize swing.

- Siandardized mating such as sallu. size ludt herats athd grasping handle.

- Two stage mating may he useful when tight tolerances are repuided for conplimb.

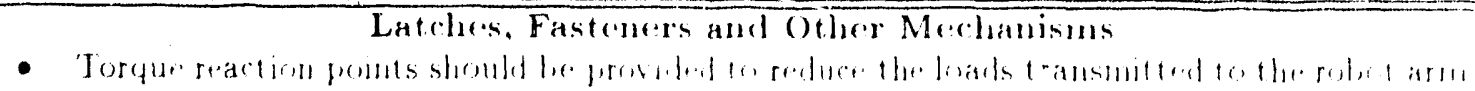
when neersary

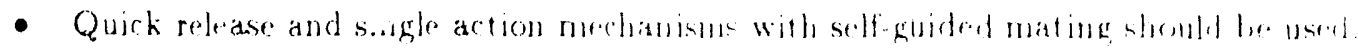

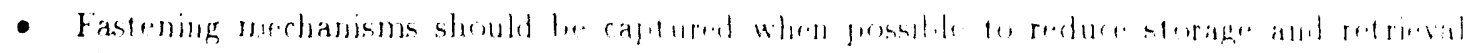
oprerations

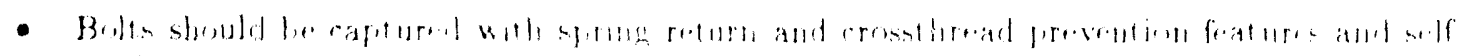
guilued mating wo sockels.

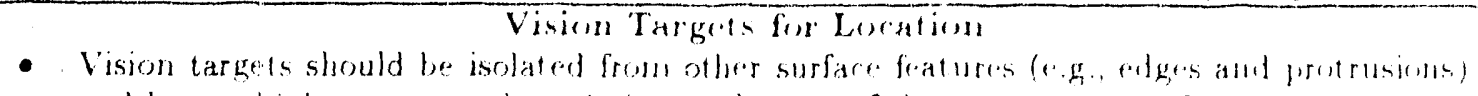
and have a high contrast color relation to the rest of the combument surfare

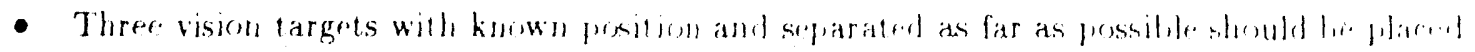
upon each movalle compousent in the rask and transperter systeme.

- Special workpoints requiring extra precisub can he provided with separate vingen targets.

- Model and serial number information markmes for all separable compeneme of the

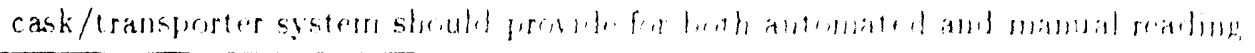


Robot approach directions and clearances aic important for lifting as well as manipulation. Overhead gantry robots typically consist of three translational axes coupled with up to three wrist-like roll axes to achieve their rated degrees of freedom. The rated weight carrying ability (i.e. payload) is usually defined by the strength of the weakest roll axis. The strength of this joint is usually far less than that of the translational axes. Thus, maximum lifting capability is provided by coupling directly to the three translational axes. This requires direct overhead clearance to lifting points on the cask.

Given the restrictive capabilities of robotic systems, design of the robot's working environment is extremely important to the success of applying robotic systems to remote handling tasks. Experience at SNL [6-9] indicates t'at modest design changes which do not change the functionality of major components can significantly affect the ability to execute various tasks robotically. Symmetries and alignment tapers for self guiding assembly reduce both the requirement for accurate parts fixturing as well as the complexity of robot control algorithms. Sclf guiding can reduce the time for robotic insertions by an order of magnitude or more over cesigns without these features [10]. In the development of a maintenance robot for a test nuclear reactor [8], two simple design changes greatly facilitated robotic operations. Two bolts were noved two inches to allow for clearance and provided with spring capture mechanisms with the result that an unbolting operation could be completed in ten seconds. Before the design change, the unbolting task was very difficult to perform robotically, requiring special tools and several minutes to complete. Similarly, a connector with push/pull locking was substituted for a bayonet connector reducing the connector assembly/disassembly time by a factor of 10. Accommodation of the limited dexterity and the sparse sensory information available to the robot roller requires attention to details and simplification of operations that result in systems that are easier to operate manually as well as robotically, 
Oscillation damped movement of suspended heavy objects [9] has shown that properly controlled crane movements can transport objects over distances of 20-30 feet in less than 10 seconds with little residual pendulum motion. Previous estimates have suggested 15 minutes would be required to accomplish such movements because of the time required to damp the pendulum oscillations induced during manual operation of cranes [11]. Designs which allow grasping of objects directly over the center of gravity, thus reducing second order pendulum effects, facilitate oscillation damped transport.

\section{ILLUSTRATIONS OF CASK DESIGN CONSIDERATIONS}

The direct application of the cask design considerations described above is illustrated by discussion of several of the mock-up designs used in the proof-of-concept robotic systems. The concepts described here were considered with regard to their capability for robotic handling. Other cask performance and licensing requirements will impose additional, perhaps conflicting, constraints on the cask design.

\section{A. Remote Radiation Survey and Analysis System (RRSAS)}

The Remote Radiation Survey and Analysis System (RRSAS) [7], completed in August, 1987, locates a half scale cask mock-up with a stereo vision system, identifies the cask using bar codes and then performs non-contact radiation and visual surveys. These are followed by a contact surface contamination survey using force controlled contact swiping of random locations on the cask surface. The radiation and surface contamination surveys were chosen for the first proofof-concept system to be built for AHTP because they required demonstration of key enabling technologies: model-based automatic planning and programming of robot movements, sensor integration which provides model updates and allows detection and possible recovery from off-normal conditions, and force control to maintain contact with the cask surfaces during contamination surveys. Figure 1 solows RRSAS and the cask mock-up. Model-based control with 


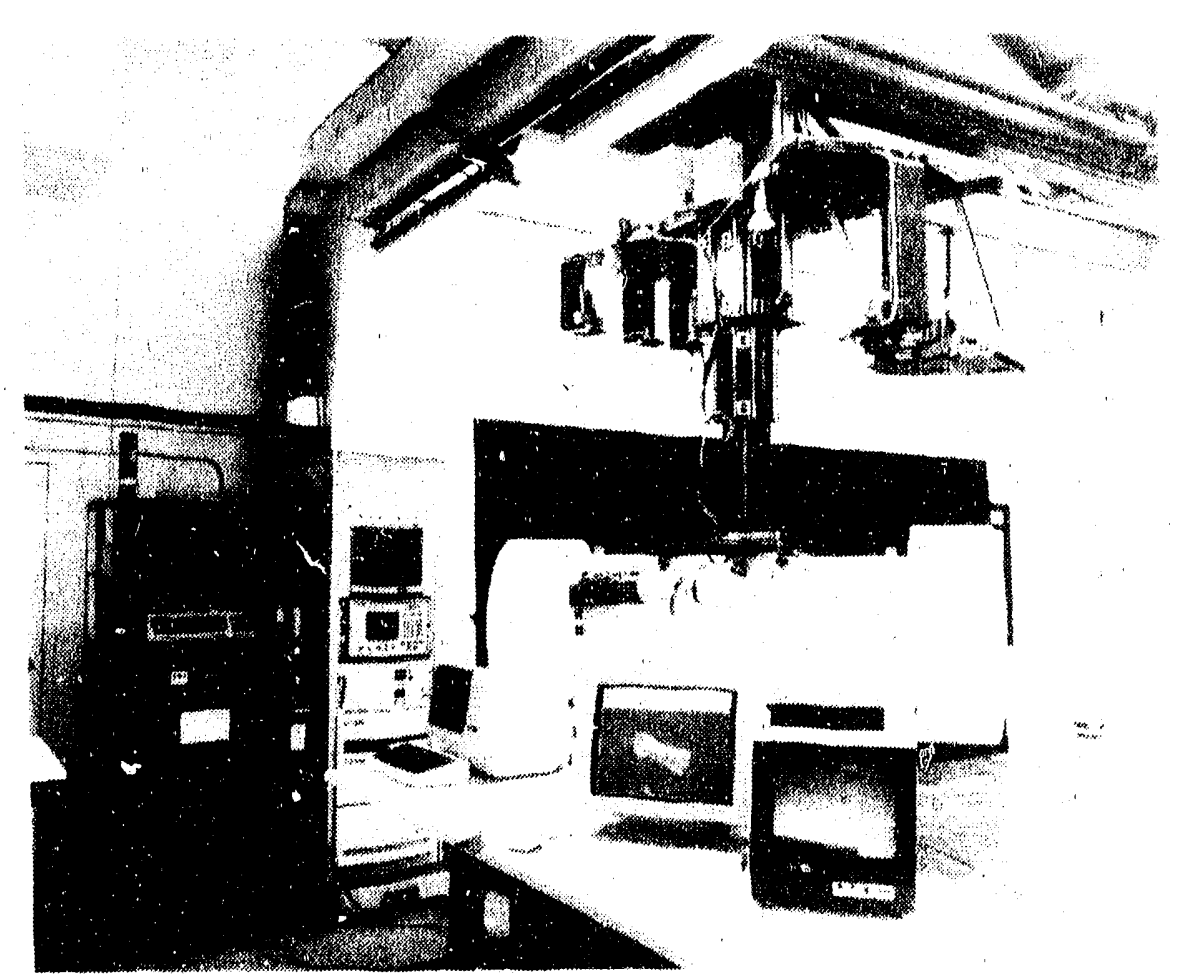

Figure 1. Remote Radiation Survey and Analysis System (RRSAS)

sensor integration permits the RRAS system to consistently perform the contamination survey using a specified swiping force $(4 \pm 1 \mathrm{lbs})$ [7]. Furthermore, automatic monitoring and recording of the operations reduces the time for record keeping with the result that RRSAS can perform the complete contamination survey faster robotically than it can be performed manually.

A primary objective of RRSAS wis $t$ e demonstration of the enabling technologies that would be used in the subsequent AHTP systems. The technologies demonstrated in RRSAS are used extensively in other robotic systems. The simple cask mock-up used for RRSAS incorporated some of the considerations summarized in Table 1. From the RRSAS project, several important cask design considerations were learned: simple geometries facilitate robot path planning; clearances are important between the impact limiters and the tiedown mockups; and high contrast vision targets against a uniform cask color provide for the vision system to locate the cask. 


\section{B. Cask Head Operations (CHO)}

The Cask Head Operations ( $\mathrm{CHO}$ ) project investigates robotic performance of cask head operations required before and after fuel unloading. These operations include leak detection, gats sampling (port cover removal/replacement and coupling/uncoupling of the sampling apparatus to the port), and bolting and unbolting operations. The CHO project has developed a modular test facility for investigating the impact of various cask design features on robotic operations. First demonstration of the CHO robotic system was in September, 1988. The CHO system has been used to develop robust algorithms for performing robotic operations such as mating a torque wrench to the various boltheads on a cask herd mock-up using force feedback. Figure 2 shows the CHO system torque wrench and the cask-head mock-up. The limited workspace of floor mounted robots such as that used in CHO makes access to side features on the cask difficult,

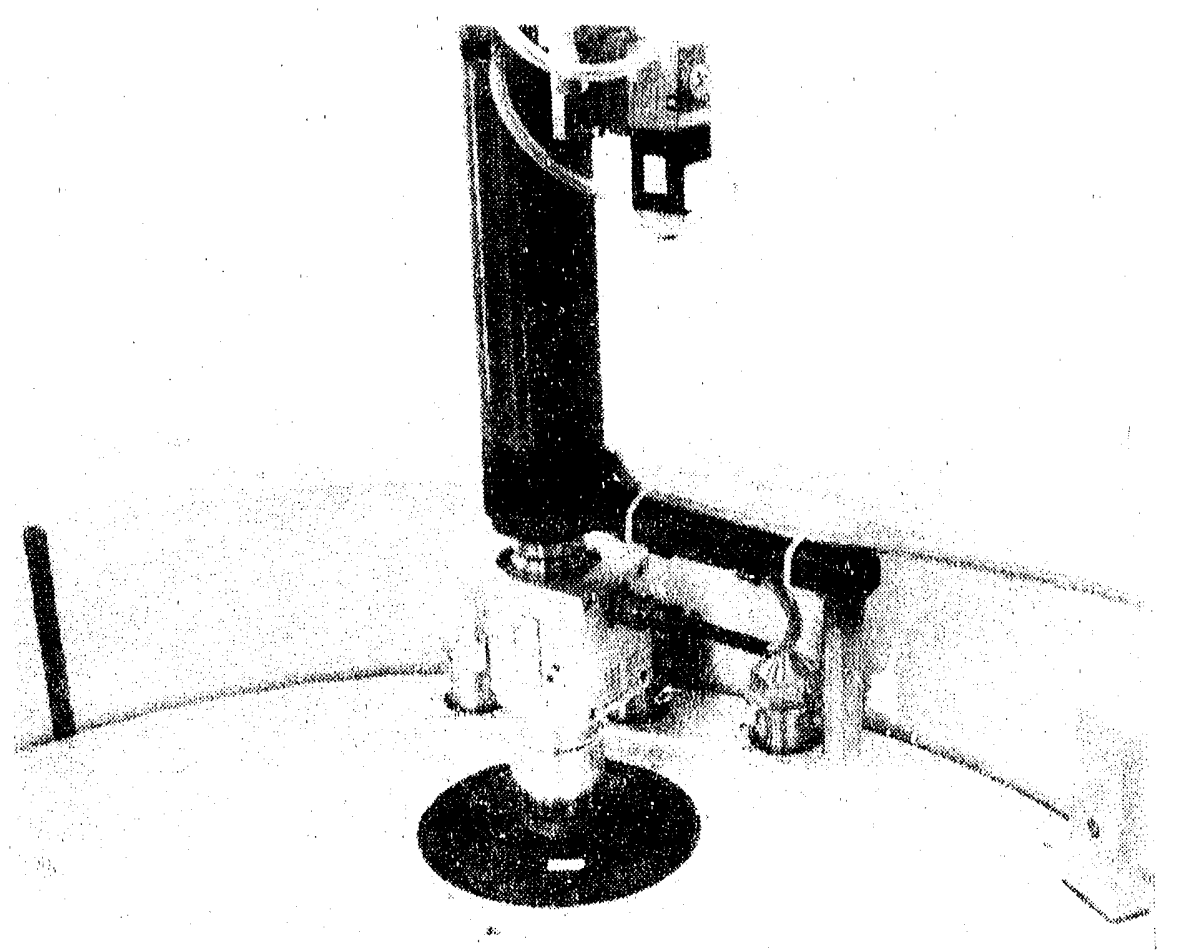

Figure 2. Cask Head Operations (CHO) System, showing torque wrench during bolting operation 
suggesting that actual cask handling facilities at a repository may be better performed using gantry type robots.

The modular design of the cask head mock-up for the CHO project permits investigation of alternate design features, including bolting systems, ports and coupling mechanisms for leak detection and gas sampling, lifting systems, and seals. The design features initially installed on the cask head mock-up shown in Figure 3 incorporate many of the design considerations summarized above in Table 1. Because of the large number of features on the mock-up (ieak test and gas ports, bolts, etc.), clen ance for the robot and its attached tools was a major consideration during the layout of the cask head mock-up. Additionally, clearance was provided for torque reaction points located in ine wortspace, with accommodation for the forque seaction bar on the wrench.

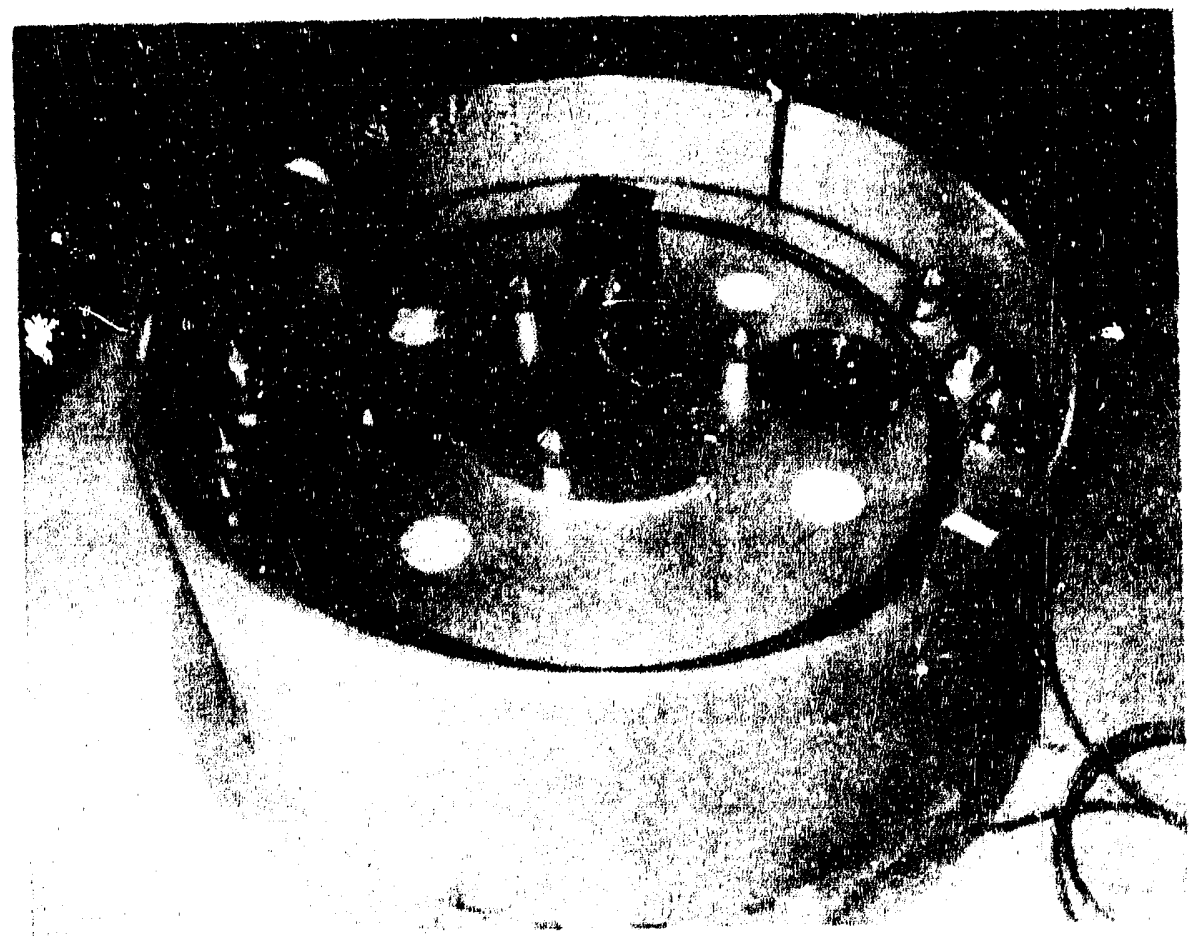

Figure 3. Cast Head Operations (CHO) System Mnch-up 
To accommodate the limited dexterity of the robot, simple push/pull mechanisms were employed for coupling to the leak detection and gas sampling ports. In addition, locking the gas sampling port cover involves operating a simple dead bolt mechanism by turning a bolt. The coupling to the leak detection and gas sampling ports is accomplished in two stages: the self-guiding first stage ensures that the coupling devices are aligned before actual coupling occurs in the final stage. For gas sampling and leak detection, couplings provide sealed mating prior to opening of valves remotely. Self-guider mating permits the use of simple compliance algorithms for engaging the separate features of the cask head mock-up. Bolt heads are tapered so that horizontal compliance alone can accommodate alignment errors. Similarly, the grip fixtures are tapered to provide both tight grip by the gripping tool and compliance during alignment. To minimize tool changes all grip locations use gripping fixtures of the same size and all bult heads are the same shape and size.

\section{Impact Limiters}

Because of the close proximity to the ends of the cask, occupational radiation exposures during the manual operations of impact limiter and cask tiedown removal can be significant, representing nearly $20 \%$ of the accumula.ed radiation dose at the repository [4]. Several projects to investigate these operations are under development. Simulations have been used to screen various conceptual designs for impact limiter and tiedown systems, and mock-ups are currently in fabrication.

The Impact Limiter Handling Project will investigate the cask design considerations associated with the robotic removal, handling, and installation of cask impact limiters. When performed robotically, these operations will include location of the limiters by machine visicn, forcecontrolled unbolting of the impact limiter from the end of the cask, attachment of the robotic manipulator's end-effector to the limiter, and removal of the limiter under hybrid force/position control. During impact limiter installation on the cask, the project will identify and evaluate methods and features required for mating the limiter to the cask, and for holding of the limiter in place during bolting operations. Two different impact limiter mock-ups will be evaluated using 
the RRSAS cask.

Many of the issues for design for robotic handling are independent of any particular design. An example of a design consideration common to many impact limiter designs is that of placement of attachment bolts. Robotic handling is facilitated by approaches normal to the cask, with sufficient clearance for robot arms and tools. Further, the bolts must be accessible within the workspace of the robot. Arrangements with the bolts radial to the cask will require multiple approach paths, which complicates path planning; some bolts may be impossible for the robot to reach. Design of a larger robot with greater reach may be more expensive than designing the cask for ease of access to all bolts. Bolt arrangements on the cask side of the limiter typically give minimal clearance for tools and arms, especially if other structures (such as lifting trunnions or the cask support) are nearby. Figures 4 and 5 show robotic handling simulations of impact limiter

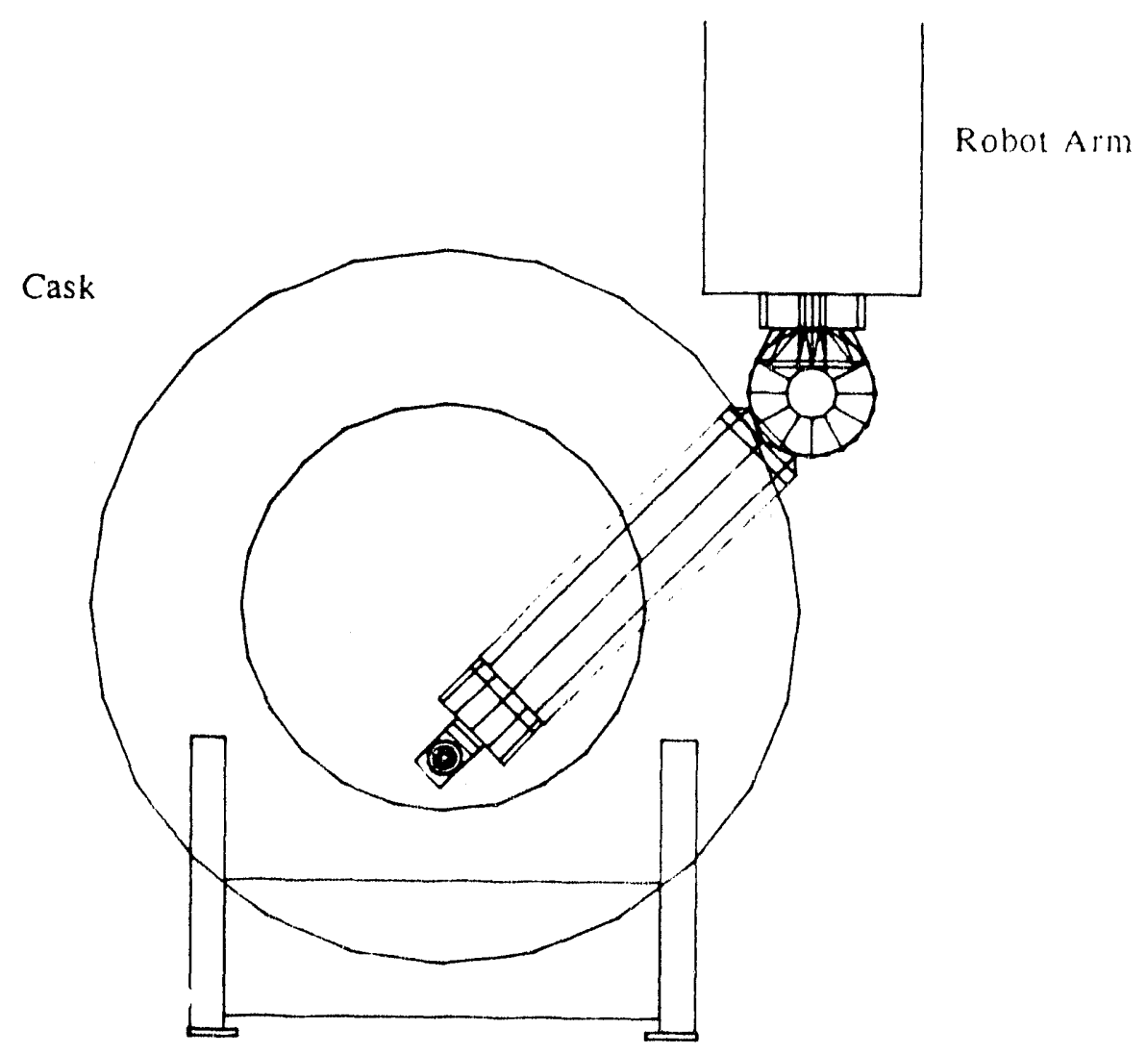

Figure 4. Cask End View. Robot Arm Approach for Bolling from End of l.miler 


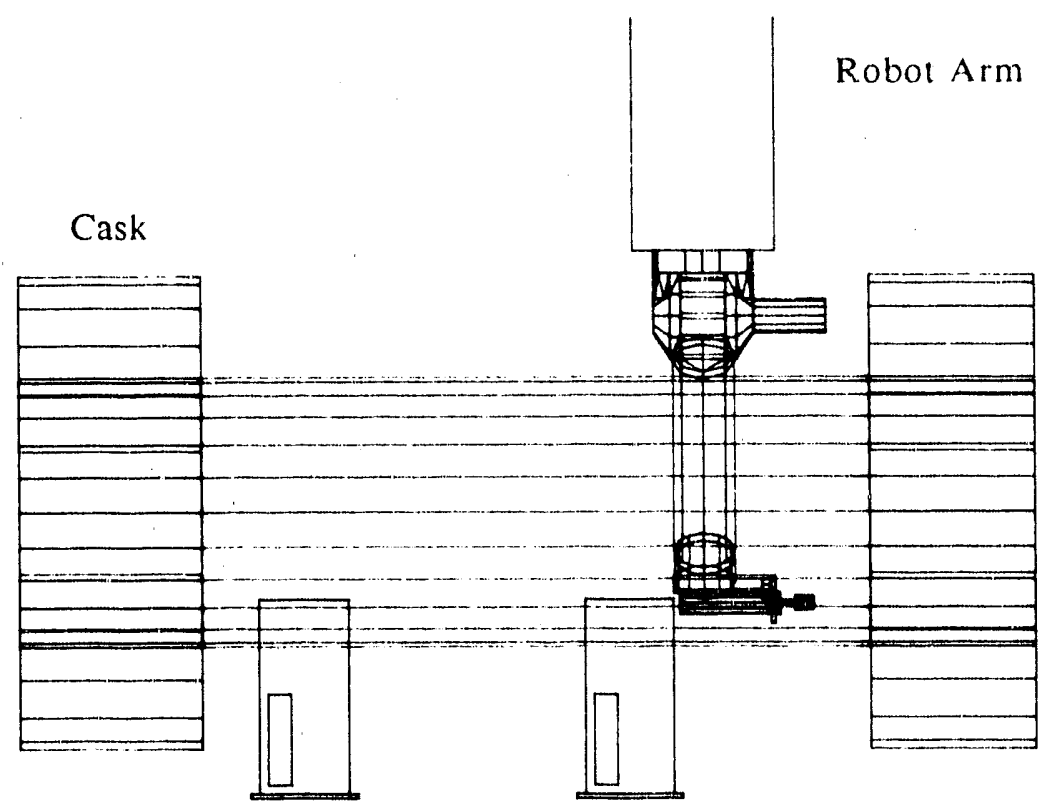

Figure 5. Cask, Side View. Robot Arm Approach for Bolting from Cask Side of Limiter

unbolting operations. This comparison demonstrates the ease in approach and access using cask end bolts (Fig. 4), as opposed to the more difficult operation when the bolts are manipulated from the cask side of the limiter (Fig. 5). The latter arrangement may also require access from underneath the cask and avoidance of the cask supports, which may complicate the robotic operation. Elimination of such difficult accesses not only improves robotic handling, but can also shorten manual tasks during a high radiation dose operation.

A nother issue common to impact limiter designs is that of the handling of the substantial weight of the limiter during bolting and unbolting operations. Typically, the last three joints of a gantry robot (such as the Cimcorp XR6100 used in RRSAS) are the weakest. Thus, for robotic handling, the preference is to lift the limiter directly above the center of gravity, thereby isolating the weakest robot joints from excess torques. Since the removal and installation will be done horizontally, some vertical support is thus required during the bolting operations. This might be done with an integral latching mechanism, or by employing two-stage mating using a set of 
alignment pins. In either case, alignment anif support are required after the robot has emplaced the limiter, while the robot changes tools to perform the bolting operation. Another possibility is to use cooperative operation between two remote handling machines, such as a crane and a robot arm. In this case, the crane would emplace the limiter and hold it in position while the arm attaches the bolts and tightens the limiter in place. The top-mounted handles shown in the mockup designs (see Fig. 6) were included to accommodate the limitations of the experimental robot used in AHTP, but are not necessarily requirements for robotic handling.

\section{Cylindrical Impact Limiter}

A mock-up of a cylindrical impact limiter was designed to model those characteristics of existing cylindrical-type limiters which are important considerations for robotic handling. With this model, robotic removal and installation operations can be tested on a traditional limiter design. A cross section of the limiter and cask is shown on the left side of Fig. 6. A handle placed on the top of the limiter, above the center of gravity, gives the robot a place to grasp and control the limiter during the handling operations.

Two sets of bolts have been placed in the model to evaluate the robotic bolting/unbolting operations. One set on the outer face of the limiter is accessible from the cask end, while the other set is on the cask side of the limiter. Because of the greater difficulty in reaching the cask side bolts, special tools are needed. The bolts use tapered heads as in the cask head mock-up to help the wrench socket align with the hex head bolt. Each bolt is captivated, spring-loaded, and constrained to move along the long axis. These features assist both robotic and manual operations by eliminating unnecessary handling. Spring activation also provides a simple indicator that the bolt has been released. Clearance between the bolts and their housing provides some allowance for misalignment.

Pins are included in this limiter mock-up in order to facilitate the alignment of bolts and holes during mating of the limiter to the cask, and to support the limiter when the robot releases the 


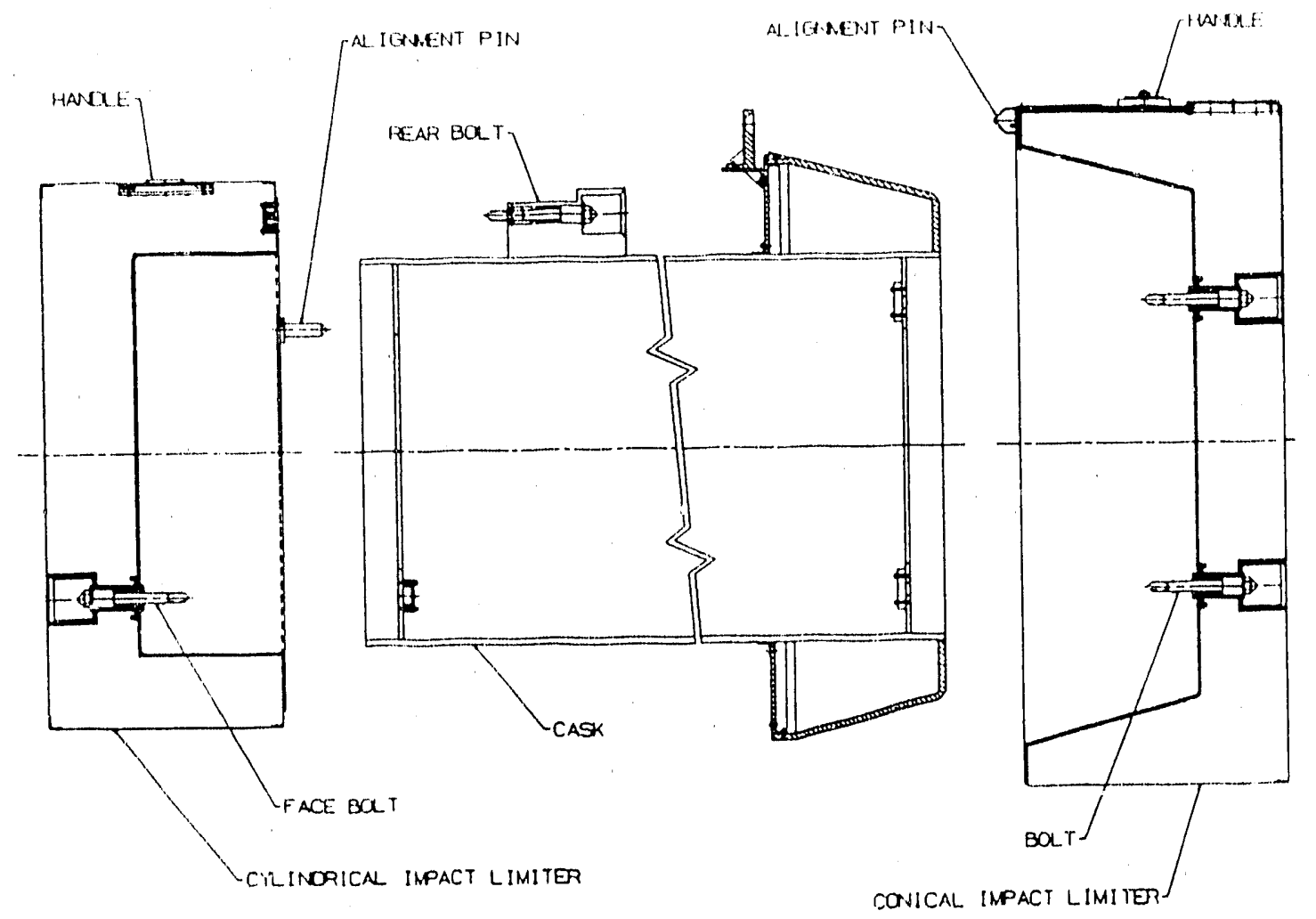

Figure 6. Cylindrical and Conical Impact Limiter Concepts

limiter and performs the bolting operation.

The clearance between the impact limiter and the cask body is one of the most important factors to be investigated in the study of cylindrical impact limiters. Mating of the limiter to the cask is an example of the classical peg-in-hole insertion problem in robotics. However, while the problem normally allows grasping along the insertion axis, in this case the grasping position is offset to the top of the limiter. The combination of an of fset grasp and small clearances may require extensive force- and position-control algorithm development to accomplish the mating operation robotically. 


\section{Conical (Tapered Mating) Impact Limiter}

A cross-sectional side view of the conical concept for a cask impact limiter is shown on the right in Fig. 6. Compared to a cylindrical design, this version of an impact limiter would simplify robotic removal and installation of the limiter on the cask. The conical design provides selfguiding between the limiter and the cask along the entire mating surface; the minimization of contact during sliding would reduce the need for highly accurate positioning. The clearance between the limiter and cask remains large until the tapers mate completely. The angle of the taper is dictated by the angle required for static friction to prevent slipping and by the repeatability and accuracy of the robot. With this configuration, forces required for mating are Ininimized, and the required level of alignment precision is reduced. This allows simpler motion algorithms and less expensive grasping hardware.

Bolting/unbolting operations are accomplished from the end of the cask along the axis of the cask. This facilitates robotic operation by providing 1) maximum clearance for robot arms and tools, 2) high accessibility in the working envelope of the robot, and 3) simple approach to the cask from one direction. By comparison, bolts oriented radially to the cask axis require complex robot approaches from multiple directions. In addition, bolts underneath the cask would be difficult to access. Similarly, bolts oriented along the cask axis but accessed from the cask side of the limiter may also require complex robotic approaches, especially underneath the cask. Robot arm and tool clearances may be difficult to maintain in this configuration. Captive bolts with self-guided mating and same size bolt heads are used throughout.

Some type of fastener may be required on the top of the limiter in order to keep the tapered device in place during bolting and unbolting operations. A latching mechanism was selected for the mock-up. The latch can be an integral part of the lift attachment plate. If spring-loaded, the latch would be released when the robot arm attaches and begins to lift the limiter. Grasping the limiter at the top rather than the side would reduce the lifting torques and hence the size of the robot arm required. If overhead wire rope cranes are used to handle the impact limiters, not 
shown in this concept), the conical mating concept reduces the positioning and alignment accuracy required for removal and installation.

\section{Tiedown Systems}

The Cask Tiedown Project will evaluate tiedown and trunnion design implications for robotic handling. This project will investigate the operations associated with tiedown release, removal, replacement, engagement, and fastening. As a first case, a quarter scale cask mock-up will be employed with a rigid strap tiedown and a locking trunnion design. Other tiedown concepts will be incorporated into the RRSAS cask mock-up for evaluation, Robotic handling and operations of the tiedown designs will include algorithms for location of the trunnions, force controlled : elease and unbolting operations, tiedown strap removal (if appropriate), and trumion release and operation.

Depending on a variety of cask design parameters, either over-the-cask strap tiedowns or trunnion tiedowns may be used to hold the cask in place on the transport vehicle. If strap tiedown mechanisms are employed, robotic handling of the strap is facilitated by using a rigid strap design. This is particularly important during robotic installaticn of a strap. The trunnion tiedown alternative uses integral locking mechanisms on the trunnions as opposed to straps. In this latter design, the trunnion is designed to be used as a cask tiedown to the transport vehicle, and also to support the weight of the cask during lifting. By servi.ig this dual purpose, additional tiedown mechanisms are minimized, thereby reducing overall weight to the system. In either case, locking and tightening mechanisms are required which should employ self -guided mating pins and bolts, captive bolts, and other engagement features defined in Table 1.

Simplicity of design and small size are important additional considerations for any tiedown mechanism. Large and complex tiedown mechanisms complicate other robotic operations, such as the visual and radiation inspection of the cask and transport system performed in RRSAS. Complexity also leads to heavier mechanisms, which add to the weight of the transporter system. 


\section{Rigid Strap Tiedown Design}

Figure 7 shows $\in$ nd and side views of a cask with a rigid strap used for an over-the-cask tiedown. For robotic removal and installation of tiedown straps, the mechanism should be rigid. In the co icept shown, a single bolt head is engaged by an approach normal to the cask's main axis. This bolt will release tension on the strap so that the strap may slide along the cask surface for a short distance. The cradle not only supports the cask from below but also has a set of pins that mate with the strap. Once the strap tension is released, the robot gripper attaches to the strap at the top and slides the strap along the cask axis to release the mating pins from the strap sides.

Installation is the reverse of removal, and relies on self-guided mating pins and a rigid strap for model-based position control of the tiedown strap and force controlled pin insertion.

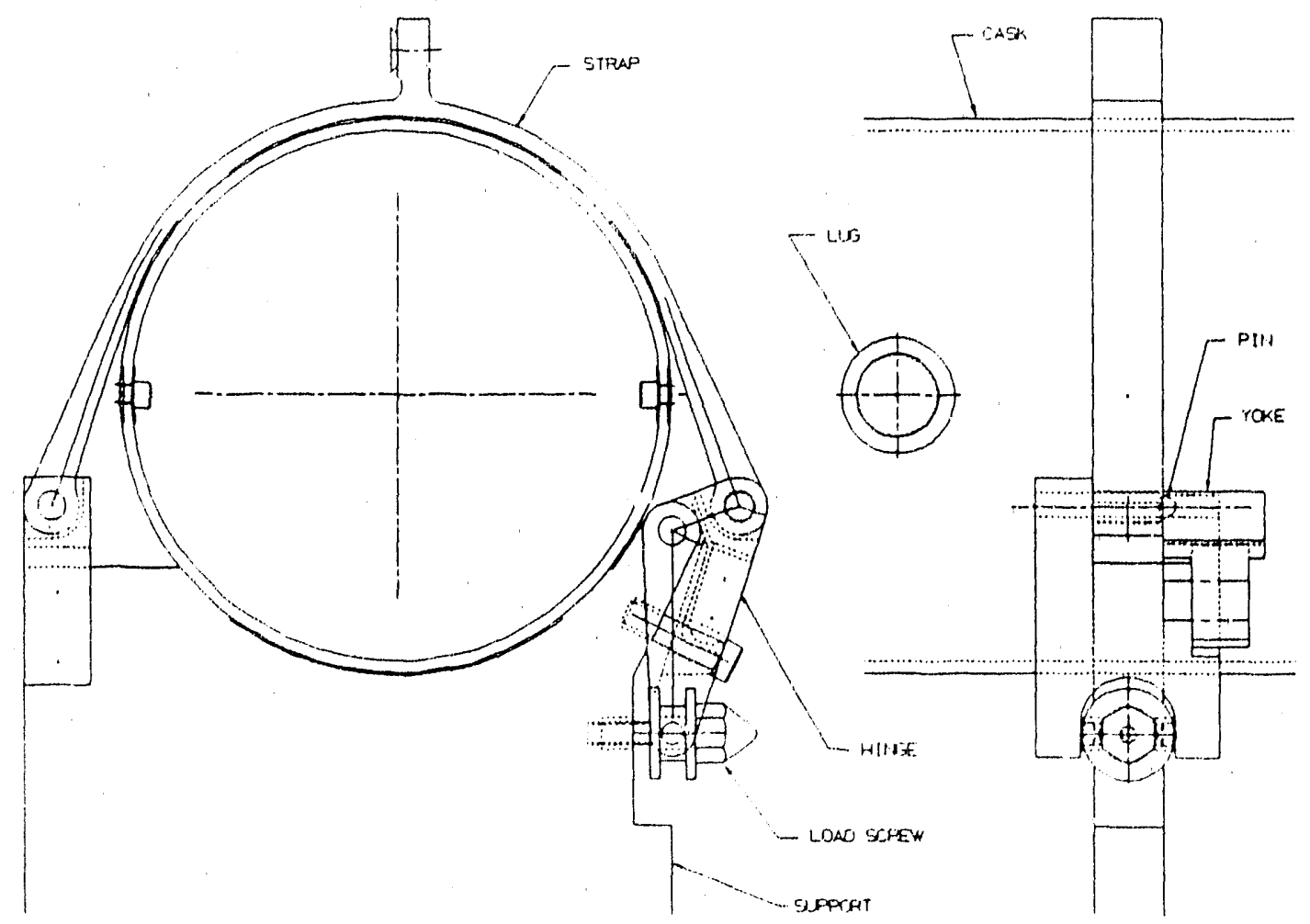

Figure \%. Rigid Strap Tiedown System 


\section{Trunnion Tiedown Design}

An alternative tiedown concept incorporates a trunnion locl ing mechanism into the trunnion support for tiedown during transportation. This mechanism supports the weight of the cask during transportation. During lifting operations, the trunnion serves either as the lifting trunnion or as the support during cask rotation to an upright position. Several trunnion tiedown concepts designed for robotic handling are under development for evaluation.

The first of these designs is shown in Fig. 8. In this "clamshell" design, the trunnion is lowered into the support mechanism which automatically captures the trunnion by action of the clarnp arms around the trunnion. The clamp is locked in place by tightening a single bolt in the screwdriven vise mechanism. No bolt or pin insertions are required. On release and removal, the bolt head is engaged either with a normal approach to the cask using a right angle tool, or sufficient clearance is provided between the cask surface and the robot tool should an approach be required along the bolt axis. Once the bolt head is loosened, the clamp mechanism is released automatically as the trunnion is lifted. Lifting action is accomplished by a crane using a yoke on the lifting trunnions. A spring keeps the arms in an open position once the trunnion has been removed.

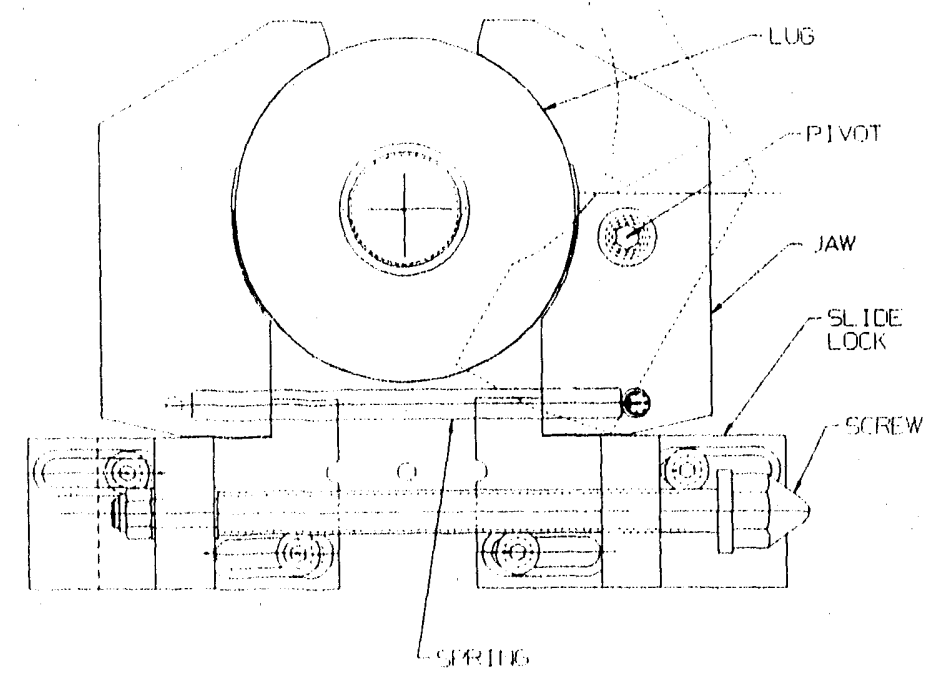

Figure 8. Trunnion Tiedown Concept -- Clamshell Design 
The second tiedown mechanism used on the trunnions is referred to as a vertical lock tiedown, shown in Fig 9. This tiedown uses a hinged strap with a vertically oriented bolt to lock down the strap mechanism to the trunnion cradle support. The strap and hinge pin are fixed together so that the hexagonal bolt head (integral to the hinge pin) can be used to rotate the strap into its locked or stored positions using the wrench. Since the wrench is instrumented to measure torque and angular displacement, the position of the strap can be determined from these measurements. The bolt head on the strap has the same dimensions as the locking bolt, thus reducing the number of tools required. The locking bolt is captured and sprung to insure a known position for the robotic bolting operations.

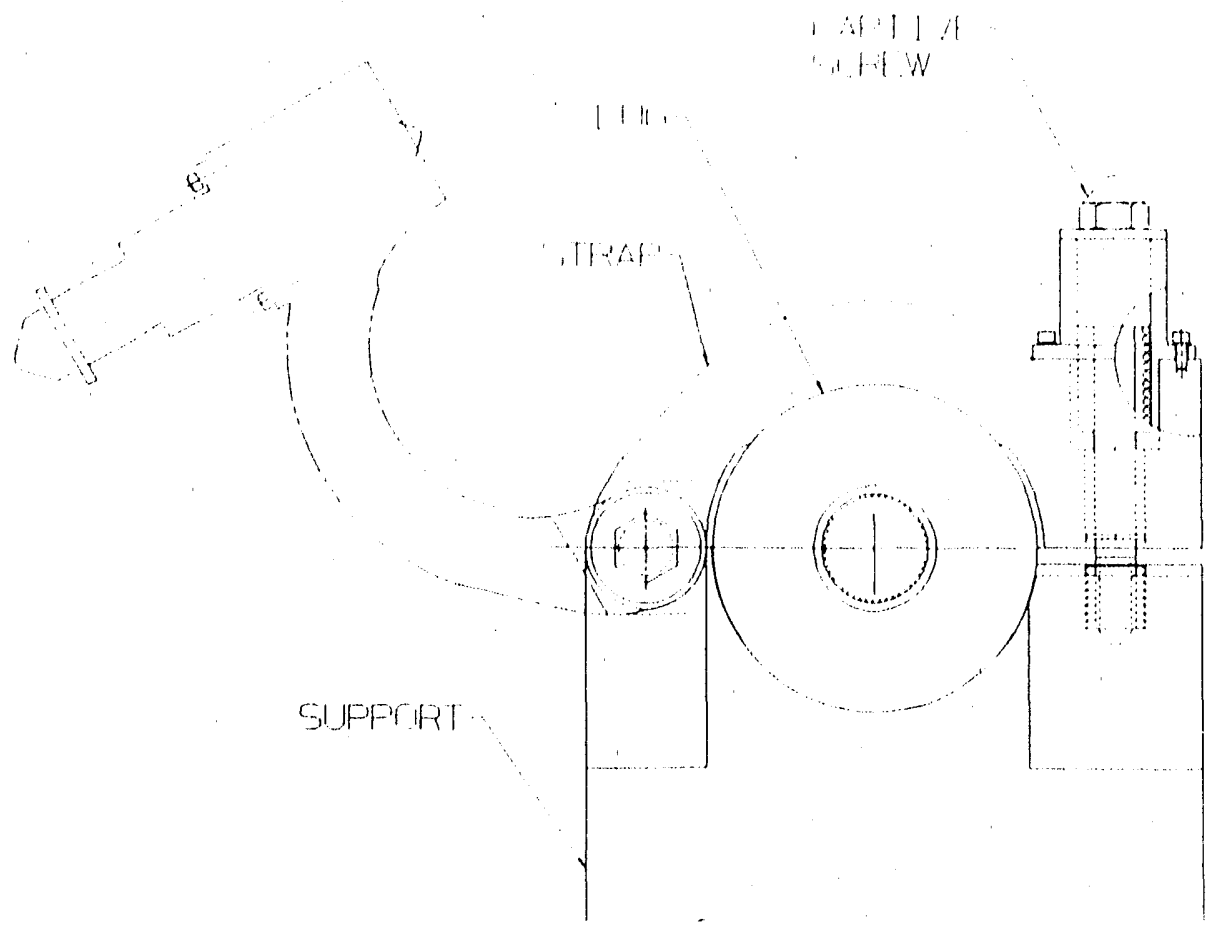

Figure 9. Vertical Lock Trunnion Tiedown Design

The third trunnion tiedown mechanism employs a horizontal lock tiedown and is shown in Fig. 10. This tiedown is similar to the vertical strap in form, but uses a trunnion-capturing feature similar to the clamshell tiedown. Thus, when the trunnion is out of the support, the strap will 


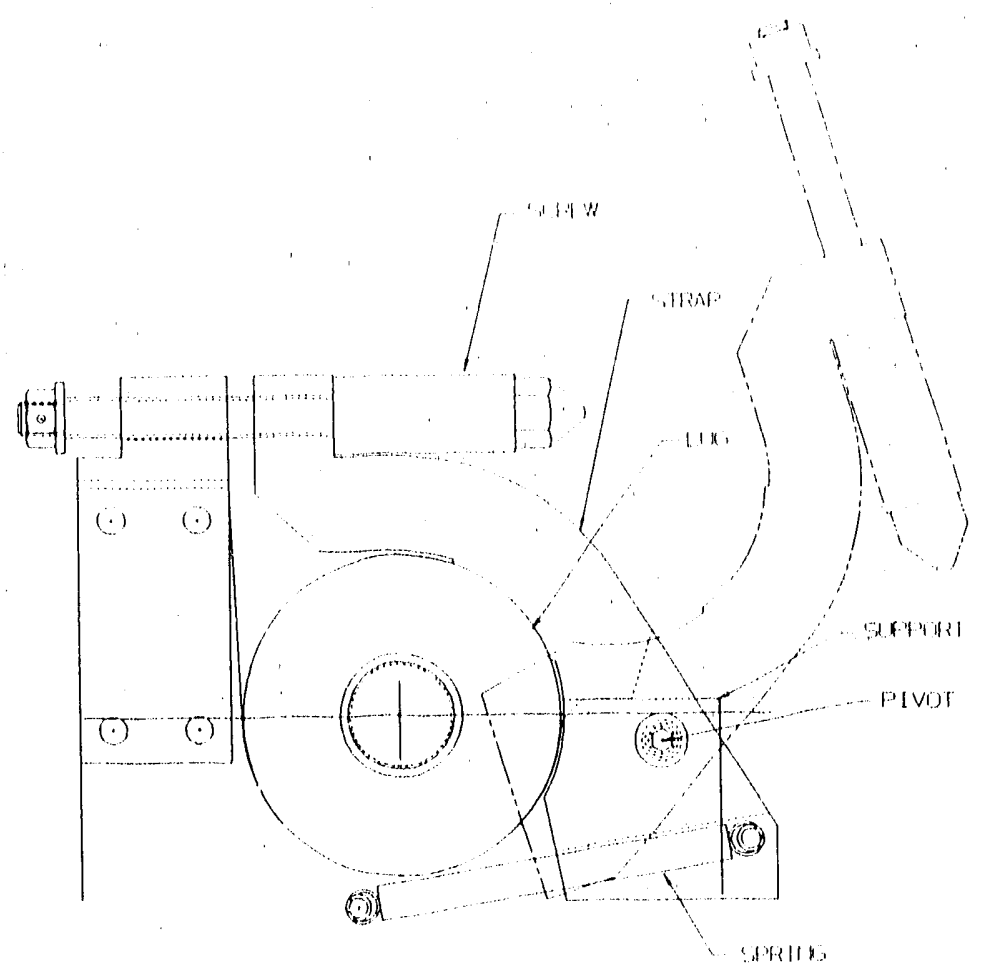

Figure 10. Horizontal Lock Trunnion Tiedown Concept.

swing out of the way by action of the spring. As the trunnion is lowered into the support cradle, the hinged strap automatically pivots into a locking position. A single bolting operation is required to lock down the trunnion, using a horizontal approach to the bolt.

\section{Dual Trunnion Tiedown Design}

Figure 11 shows a dual trunnion tiedown concept which can be employed on the pivot end of the cask. This simple design employs a pair of closely spaced trunnions on each side of the cask. The distal trunnion is shorter and smaller in diameter than the medial trunnion. As the cask is lowered into its resting position, the distal trunnion passes through a groove in the storage cadle. The medial trunnion then comes to rest in the storage cradle. As the cask is rotated into its prone position, the distal trunnion rotates up towards a stop. This stop and cradle combination locks the 
cask so that it is capt"red axially, laterally, and vertically. An adjustment screw on the stop allows for periodic adjustment. This simple concept contains no moving parts, making it easy to implement and maintain.

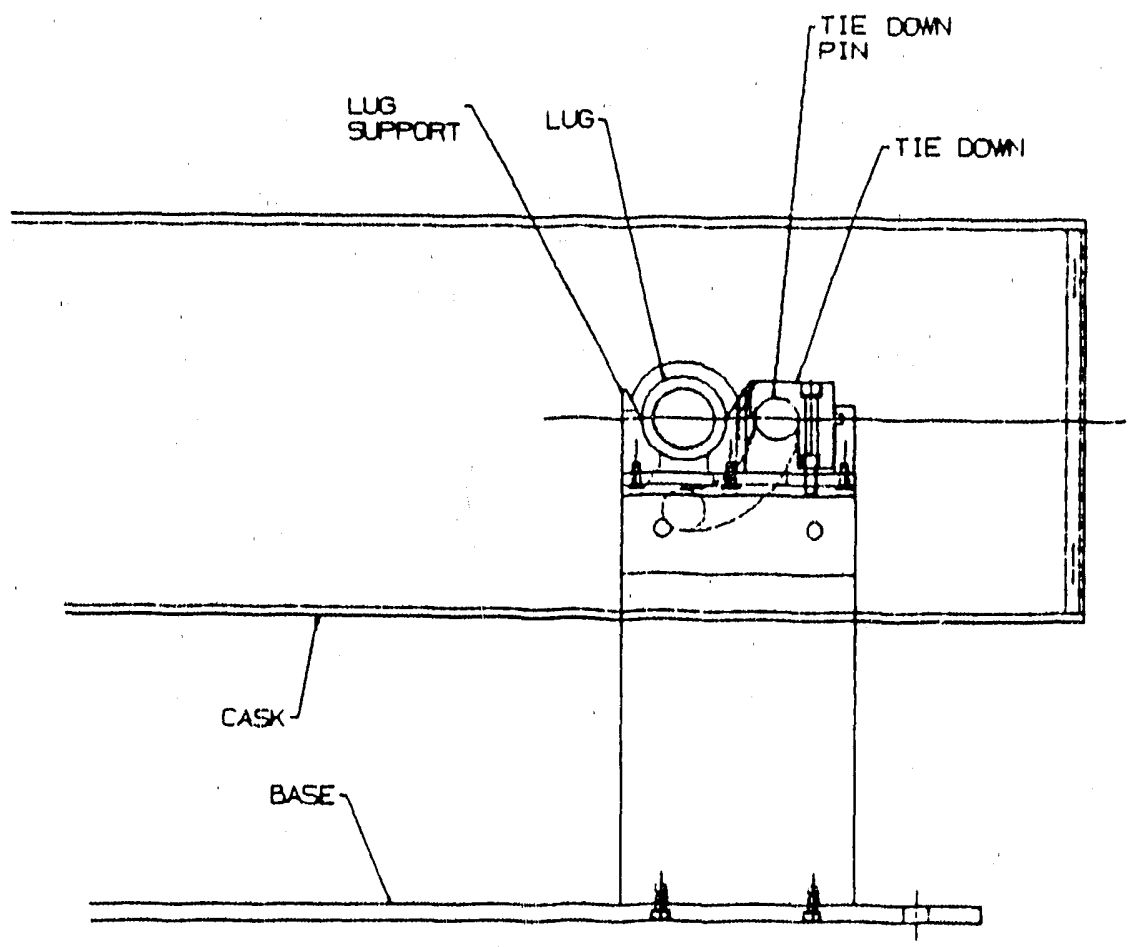

Figure 11. Dual Trunnion Tiedown Concept. Cask shown in horizontal position. Dashed curve shows distal trunnion in upright position.

\section{REVIEW OF PRELIMINARY CASK DESIGN CONCEPTS}

This section reviews handling concepts being explored during the preliminary design of transportation casks for spent fuel. All concepts are subject to change during the preliminary design development. Current examples are taken from the handling concepts to illustrate those which are conducive to remote and robotic handling, and others which may be improved upon. 
A. Inspection

When a transportation cask arrives at a receiving facility such as a repository, one of the first operations to be performeri is a security and radiological inspection. Inspections may be performed at various stages of handling including upon receipt and just prior to removal of the cask from the transporter. It is important to provide good approaches and maneuvering space for a robot manipulator to execute these inspections.

For example, one preliminary design proposes a rail car with sides approximately 27 inches from the cask outer wall, and extending above the centerline of the cask. The top and ends of the cask and impact limiters are easily accessed by an inspecting manipulator. However, for access to the cask underside, the manipulator would be required to take a difficult path threading through the gap between the car side and cask. Further, this gap width may not ke sufficient to allow maneuvering of the manipulator arm.

\section{B. Personnel Barriers}

One of the first pieces of equipment to be removed at a handling facility is the personnel barrier. The ease with which the barrier is released and retracted, the equipment required, and the storage location at a receiving site are criteria by which the barriers are judged from the handling perspective.

One preliminary design proposes a personnel barrier consisting of roll-up doors which rise from a storage location in the tiedown skid bottom, encircling the cask. A rotating input is required for operation. Another concept uses a clamshell arrangement, should a personnel barrier be required, that spans between the impact limiters and would remain on the trailer for storage. The main advantage of these concepts is that installation and removal of the barriers may be accomplistied by the relatively simple action of a single piece of equipment, such as a robot with a power wrench. A secondary advantage is that both barriers remain on the transporter in a facility where multiple units are processed simultaneously and storage space may be minimal. 
In many designs, personnel barriers are typically removed and stored away from the transporter. In these cases, the number of operations required for a slease and removal from the transporter should be minimized, and some simple means of al:gnment chnuld be provided. As an example, one design employs a one-piece personnel barrier with four captive bolts. The removal operation may require two pieces of equipment: a robot with proper tooling to release the bolts and a crane to remove the limiter. Since the bolts are captive, bolt storage and retrieval operations are eliminated. Re-installation would be aided by some means of guiding the barrier into the proper orientation.

\section{Impact Limiters}

Impact limiter handling includes methods of attachment to the cask, alignment of the limiter with the cask during installation, and movement and storage concerns. A robotic manipulator should be able to accomplish movement, alignment and attachment tasks with a minimal number of operations and support equipment.

Many preliminary designs, aploy the use of bolts to attach the impact limiters to the cask. The common end-on approach to bolting appears acceptable, provided adequate clearance is present for maneuvering the manipulator, tools and extensions required. One preliminary design proposes a quick-disconnect method for impact limiters with approaches from the cask side, and another proposes use of four pins in each limiter, inserted from the cask ends. Table 1 should be consulted as further detail is developed.

Another design requires inserting four bolts through brackets on the cask into the back of each impact limiter, as opposed to the ends. Graphic simulation has indicated that tool clearances make the bolt insertion operation difficul: (see Figure 5). This problem may be overcome by orienting the bolts at a 45 degree angle from the cask. The brackets on the cask serve as an obstacle in the cask computer model, and would complicate automatic robot path planning. 
Alignment considerations have been incorporated in the preliminary designs. One concept uses a keyed cask with a keyway in the limiter. The keyed approach together with the square cross section of the cask would provide consistent alignment. Another concept employs a ring and groove alignment configuration to complete the axial alignment.

None of the current concepts fully addresses the difficulty of fitting the impact limiter over the cask end. With clearance gaps ranging from $1 / 10$ to $1 / 4$ inch between the limiters and cask body, friction, cocking, misalignment, and dimensional tolerances of the limiter could result in significant removal and installation problems. A larger gap would be beneficial from the handling perspective, while a smaller gap is preferred from structural considerations. The stepped configuration of one design concept provides larger clearances for a significant portion of the limiter travel, easing installation. Another cask concept has a taper near the end of limiter travel, which approaches the tapered alignment concept presented earlier. The taper assists in final axial alignment and reduces the final gap between limiter and cask walls.

For automated removal and replacement of the impact limiters, integral sliding mechanisms on the transporter may be preferable. Permanently aligned mechanisms could assist in the alignment and placement of the limiters by holding them in the proper attitude while sliding them into place. Such mechanisms could reverse direction for limiter removal, and provide on transporter storage for the limiters during cask handling.

However, other considerations may not allow such mechanisms to be integral to the transporter. In this case, some means of attaching lifting and guidance mechanisms to the limiters must be provided. Hardware that allows rigid lifting over the center of gravity and is integral to the limiters would be preferred, if acceptable from a structural and thermal design viewpoint. The rigidity allows greater robotic alignment capability and the integral hardware minimizes attachment and storage/retrieval operations. 
D. Tiedowns

Most current designs use a tiedown concept which secures the cask trunnions to supports on a transporter or transport skid. Desirable configurations for handling allow ease of access and operation, as well as minimal equipment requirements.

As an example, one concept uses a device which is reasonably simple to manipulate. The rear support clamp has an arm which swings into place over the trunnion, which is resting in a cradle. The arm is then pinned on the side opposite the hinge and a bolt tightened down onto the trunnion. The pin is suspended by wire or cable, and the tightening bolt approached from the top.

The manipulator approaches to this tiedown and the final tightening appear reasonable. Location and retrieval of the suspended pin is perhaps the most difficult operation for this tiedown. Some means of retaining the pin in a known position should be provided. A second improvement would be the attechment of a bolt head to the swing arm at its pivot point. This would provide a means of moving the arm with a socket attachment from a known point, while robot torque sensors could recognize the extreme positions of the arm.

The front trunnion is clamped in a cradle by a U-shaped clamp which, when released, swings outward from the axis of the cask and slides downward. To attach the tiedown, the clamp is swung over the trunnion and then lowered into position. Two captured bolts are then tightened into the lower part of the trunnion cradle. Though the bolting operation is simple, this tiedown has no fixed point to which a robot might go to remove or emplace the clamp. The slide permits the clamp pivot point to move, making it difficult to position the clamp. A bolt head at the pivot point with some cam or linkage action would better define the clamp movement with respect to a fixed location, thus improving remote handling. 
Another concept uses a female or socket trunnion at the pivot point which engages a stud on the rear support. The cask is then lowered into the horizontal position, and the front tiedown installed. This arrangement eliminates all rear tiedown operations after initial alignment of the socket trunnion, thus simplifying handling at this stage.

One tiedown system concept utilizes removable vertical restraints over the cask body. The current concept calls for threaded attachment of the restraints to the rail car deck at four points. This configuration is similar to the strap tiedown mock-up described earlier, in that a strap is lowered over the cask and secured below. The mock-up strap is rigid and may be aligned on its pins relatively easily. A single turning action is then required to secure the tiedown. The vertical restraints may benefit from rigidity sufficient to prevent large oscillations during alignment. However, this design may be changed to utilize four shear pins which would be inserted from the side, in which case the shear pins would anchor the cask to supports.

Another design secures the trunnions to the transport skid. The transport skid itself will be released from the rail car, and the cask/skid unit removed prior to impact limiter removal and cask uprighting. This requires handling steps both to release the skid and the trunnions, as well as multiple manipulators or a manipulator with a work volume sufficient to reach both the rail car and the cask/skid unit.

\section{E. Ports}

All cask designs currently have one or two ports in the lid for gas sampling, venting and/or purging. All ports have quick-disconnect fittings; most use push-pull actions. The ports are recessed and provided with covers. Covers require bolting, screwing, or bayonet action, all actuated from the cask end. Minimization of operations and parts as well as capturing fasteners is recommended for ease of handling and storage of removed components.

If drain ports are to be utilized during remote handling of the cask, the location of the ports and 
accompanying leak check ports becomes an issue. For example, if a single port is available for cavity gas purging or cooling, the drain port may be required to allow circulation. Or, the seals of the drain port might require checking each time the cask is loaded or unloaded. In such cases, lid-mounted drain ports would be an advantage. Bottom drains would require additional manipulators near the bottom, or manipulators with extended reach, as well as facility design modification, to allow access to the ports. One design places the drain port in the lid, operating much the same as the gas sampling port. Another avoids the issue by providing iwo ports for circulation, while passing the drain line through the shield plug but not penetrating the lid. The other three designs currently place the drain outlet at the cask bottom.

Leak check ports are also provided in the lid for closure seals and port cavity seals in each design, and at the bottom of the cask in at least one case for drain seal verification. These ports should also have quick-disconnect fittings where possible. One concept uses a special plug and valve arrangement which would require complex tool motion. Development of an automated tool would be required to prevent time-consuming complex motion and tool changes.

\section{F. Closures}

In many designs, the closure lids are bolted using captured bolts approached from the end of the cask. One design uses a smooth round bolt head for security reasons, which would require a special tool. Another secures the closure with a hydraulic wedge-lock device. Four hydraulic connections would be made remotely, eliminating bolting and perhaps simplifying the closure lid removal and installation. A plug in the side of the upper cask forging must be removed and stored, and the fittings passed through the cask side into a recessed area of the lid for connection. The fittings would be disengaged prior to lid removal, reengaged for lid reinstallation, and again disengaged and the plug replaced for shipment. Care should be taken not to require complex motion to engage fittings. Fasteners used for plug attachment should also be minimized and captured. 
Lif ting of the lids in some concepts is accomplished by round pintles on the center of the lids. Pintles provide a rigid connection, which allows remote equipment to maintain better control over lid motion. They may, however, require additional ancillary equipment to engage them.

Some preliminary designs have also incorporated lid alignment mechanisms. In one case, the cask has a square cross section, which visually assists alignment, and shear pins which will guide the lid into final position. Another concept utilizes one long and one short alignment pin, augmented by sharp-contrasting visual marks. The pins and unique shapes should provide sufficient force-feedback and visual information to a robot to successfully install the closure lids.

\section{G. Cask Lifting Method}

Most cask designs are lifted with male redundant trunnions near the top of the cask. Placement of the trunnions such that the cask hangs vertically is important for programmed swing-free movement of the casks. One concept requires the removal of the lifting trunnions prior to installation of impact limiters, each of which is attached with a minimum of 6 bolts. These extra operations may increase the time required for turnaround at a facility. In all other designs, the trunnions are permanent or removed only for maintenance.

\section{CONCLUSIONS}

Experience with the development and operation of the proof-of-concept robotic systems of the Advanced Handing Technologies Project indicates that robotic systems have significant potential for improved handling of nuclear waste transport casks. Design detail is critical to the successful application of robotic systems to remote handling. Thus, cask designers should consider the needs of robotic handling during design in the event that cask handling facilities use robotic systems. In most instances, minor design modifications can significantly impact the feasibility of robotic handling and the design process becomes one of attention to detail rather than of radical alterations of concepts. 
The main conclusions from AHTP to date regarding design for remote handling are: 1) incorporation of cask system design features which facilitate robotic cask handling can be achieved with minimal impact on cask functional features, 2) proper cask design allows robotic cask handling operations from manipulation of cask tiedown mechanisms to radiation surveys to be performed quickly and reliably without direct human intervention [7], and 3) design for remote handling also facilitates manual handling operations.

\section{ACKNOWLEDGEMENTS}

The authors acknowledge the continuing support of Mr. William Lake of the U.S. Department of Energy Office of Civilian Radioactive Waste Management, and Mr. Lawrence Harmon and Mr. Frank Falci of the Office of Environmental Restoration and Waste Management. We also thank Ms. Margaret Fisher and Mr. Mark Pellechi of the U.S. DOE Idaho Operations Office and Mr. Kenneth Golliher of the Albuquerque Operations Office for their support and guidance. 


\section{REFERENCES}

1. DOE, Requirements for Radiation, Order 5980:1 A, Chapter X1, Washington, DC (1987).

2. J. M. Griesmeyer and S. Thunborg, Remote Cask Handling and Implications for Cask System Design, Sandia National Laboratories, SAND87-2670, Albuquerque, NM (1988).

3. D. R. Strip, Robotic Handling of Spent Fuel Shipping Casks: Preliminary Assessment of Cask Design Impacts and Technology Development Needs, Sandia National Laboratories, SAND86-2470, Albuquerque, NM (1987).

4. K. J. Schneider, et al, Analysis of Radiation Doses from Operation of Postulated Commercial Spent Fuel Transportation Systems, DOE-CH/TPO-001, U.S. Department of Energy, Washington, DC (1987).

5. J. D. Berger, B. C. Gneiting and T. L. Sanders, "Use of Robotics for Radioactive Waste Shipping and Receiving", Packaging and Transportation of Radioactive Materials (PATRAM '86), 485-495, Davos, Switzerland (1986).

6. B. J. Petterson and J. F. Jones, "Force Control of a Robot for Surface Contamination Detection," Proceedings, 35th Conference on Remote Systems Technology (1987).

7. S. Thunborg, "A Robotic Radiation Survey and Analysis System," Proceedings, 35th Conference on Femote Systems Technology (1987).

8. S. Thunborg, "A Remote Maintenance Robot System for a Pulsed Nuclear Reactor," Proceedings of 1986 IEEE International Conference on Robotics and Automation, San Francisco, CA (1986).

9. J. F. Jones and B. J. Petterson, "Oscillation Damped Movement of Suspended Objects," Proceedings of 1988 IEEE Conference on Robotics and Automation (1988).

10. D. R. Strip, "Insertions Using Geometric Analysis and Hybrid Force-Position Control on a PUMA 560 with VAL II," Proceedings of Sixth National Conference on Artificial Intelligence, Seattle, WA (1987).

11. D. H. Nyman, et al., Concept for Applying Remote Systems Technolosy to the Transportation Repository Interface, Hanford Engineering Development Laboratory and Sandia National Laboratories, Preliminary Draft (1987). 

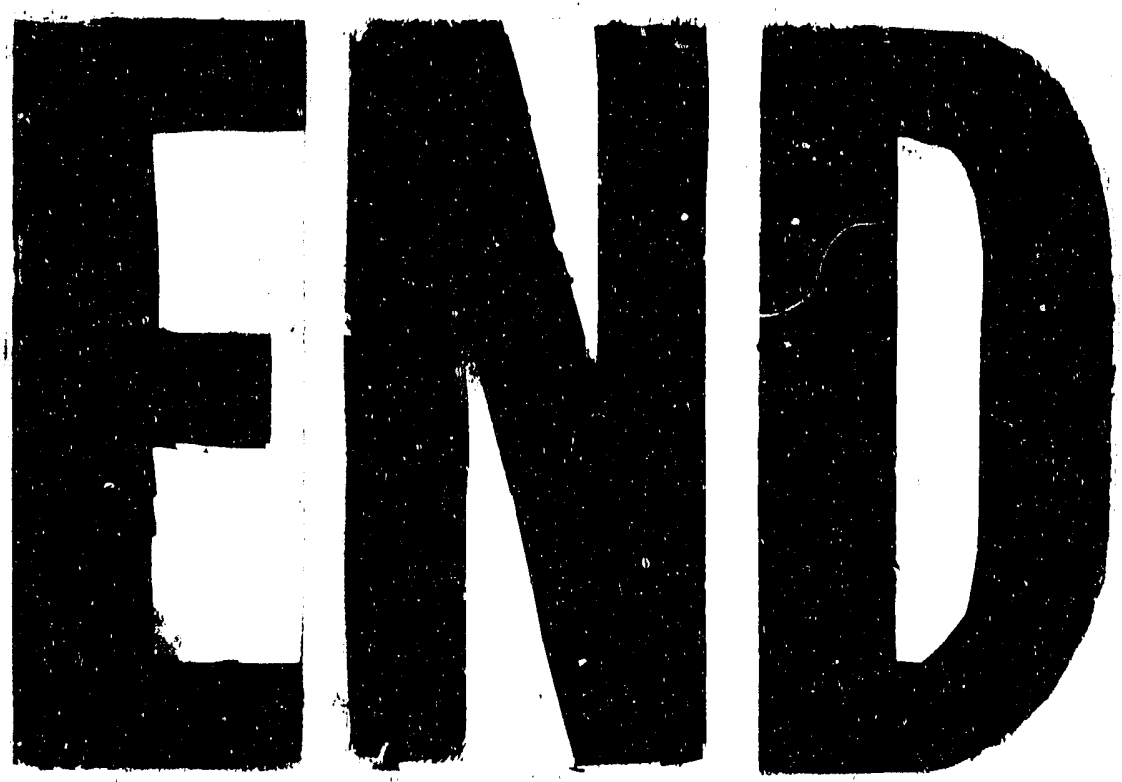

4
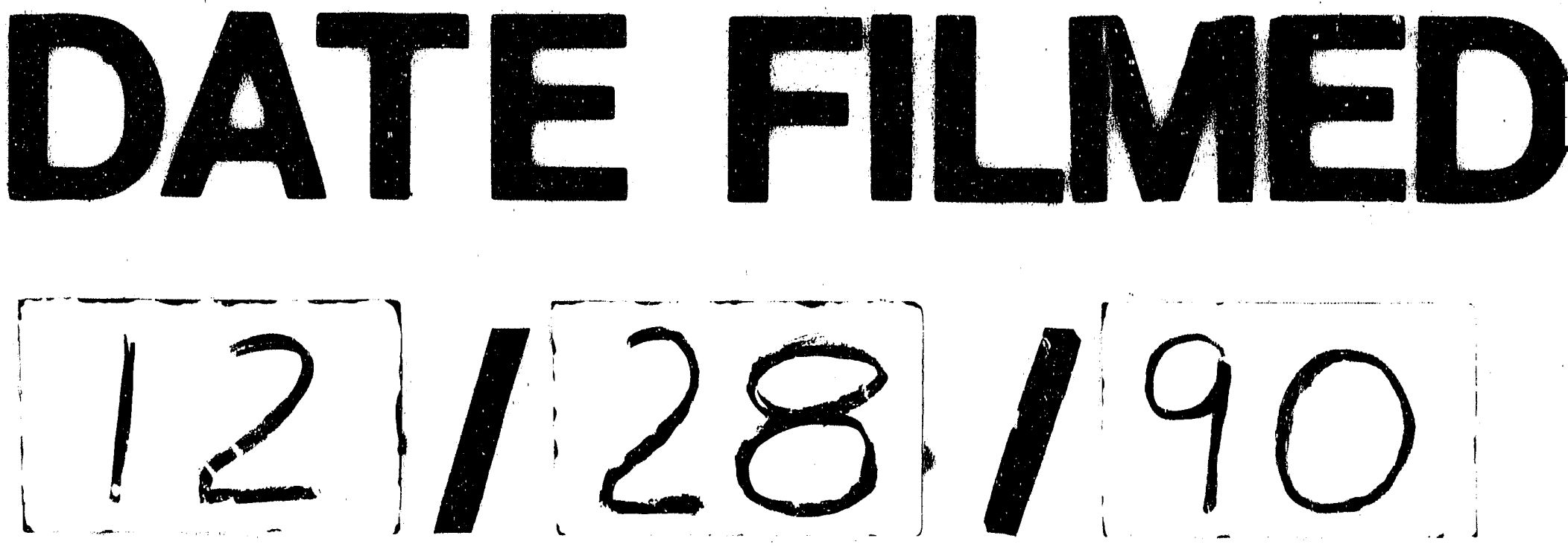
